\title{
New therapies and management strategies in the treatment of asthma: patient-focused developments
}

\author{
Joshua Agbetile \\ Ruth Green \\ Department of Respiratory Medicine \\ and Thoracic Surgery, Institute for \\ Lung Health, Glenfield Hospital, \\ Leicester, UK
}

This article was published in the following Dove Press journal: Journal of Asthma and Allergy

24 December 2010

Number of times this article has been viewed

\begin{abstract}
It is increasingly recognized that large proportions of patients with asthma remain poorly controlled with daily symptoms, limitation in activities, or severe exacerbations despite traditional treatment with inhaled corticosteroids and other agents. This suggests that there is considerable scope for the refinement of traditional guidelines on the use of inhaled therapies in asthma and also a need for the development of novel therapeutic agents, particularly for the treatment of severe asthma. This review aims to discuss a range of emerging treatment approaches in asthma. Firstly, we will set the scene by highlighting the importance of achieving good asthma control in a patient-focused manner and discussing recent work that has furthered our understanding of asthma phenotypes and paved the way for patient-specific treatments. Secondly, we will review new strategies to better use the existing therapies such as inhaled corticosteroids and long-acting $\beta_{2}$-agonists that remain the mainstay of treatment for most patients. Finally, we will review the novel therapies that are becoming available, both pharmacological and interventional, and discuss their likely place in the management of this complex disease.
\end{abstract}

Keywords: asthma, treatments, classification, phenotypes, management

\section{Introduction}

Asthma is largely regarded as a chronic inflammatory respiratory disease manifesting in variable airflow obstruction and symptoms of cough, wheeze, and dyspnea. This definition continues to undergo refinement in concert with developments in pathophysiology, immunology, and pharmacology. ${ }^{1}$ The infiltration of airway tissues with increased numbers of eosinophils, a hallmark of allergic disease, is also seen in asthma. ${ }^{2}$ Although debate continues as to the role of these inflammatory cells in mediating the expression of asthma, little doubt remains to the long-known efficacy of glucocorticoids in reducing both the blood and airway eosinophilia with consequent improvements in symptoms and lung function, ${ }^{3,4}$ and an attenuation in its decline. ${ }^{5}$

Most patients with asthma achieve good disease control with principal use of inhaled corticosteroids and long-acting $\beta_{2}$-adrenoceptor agonists (LABAs) that are the mainstay of asthma therapy. These therapies, however, unfortunately fail to afford a significant proportion of patients with good control of their symptoms or prevent severe exacerbations.

There are a number of possible reasons for this limitation in the efficacy of traditional therapies, including 1) a failure of traditional guidelines to reflect patients' own priorities of asthma control; 2) inappropriate timing of the introduction of treatments or the use of inadequate doses; 3) a poor understanding of different asthma subgroups, which due to their distinct pathophysiology have different pharmacological responses; 
4) limitations in the ability of patients to adhere to prescribed regimens; and 5) a proportion of patients genuinely having severe disease who are resistant to treatment (difficult-totreat asthma). This review will outline a number of strategies that are now recommended to address these limitations in asthma management. We will highlight the important goals in asthma management, offer definitions of difficult-to-treat asthma, and present the background to the development of our understanding of asthma phenotypes before reviewing specific management strategies and novel therapeutic options.

\section{Importance of asthma control and preventing exacerbations}

The goal of achieving good asthma control has become increasingly important with the recognition of its increasing prevalence in the general population. ${ }^{6}$ Given that not all emergency visits for asthma or exacerbations can be avoided, they represent a high cost in terms of a poorer quality of life, days off work or school, and the consequent financial loss while poor symptom control invariably gives rise to increased health care utilization. Emergency hospital admissions, for example, are significantly costly, accounting for $£ 61$ million of the estimated $£ 1$ billion cost of asthma to the NHS each year in the UK. ${ }^{7}$ In addition, although severe asthma accounts for $<5 \%$ of asthma in the general population, it consumes a disproportionate share of resources, ${ }^{8}$ with associated health care expenditures in severe asthma being more than 6 times those of mild asthma. ${ }^{9}$ That said, it is increasingly recognized that although severe exacerbations and hospital admissions represent the extreme of asthma morbidity, many patients with relatively mild asthma continue to experience unacceptable levels of daily symptoms, which significantly impacts their day-to-day activities and health status. ${ }^{10,11}$ Consequently, current asthma treatment guidelines (BTS/ SIGN 2009, ${ }^{12}$ ATS/ERS joints statement, ${ }^{13}$ and GINA ${ }^{14}$ ) have been updated to highlight the importance of adjusting asthma therapy with the aim of attempting to prevent severe exacerbations and admissions while also minimizing daily symptoms and maximizing quality of life. They also recognize the importance of considering the likelihood of future deteriorations in asthma control when reviewing treatment regimens for individual patients. ${ }^{15}$

\section{Difficult-to-treat asthma}

Severe asthma represents an extreme in the spectrum of the asthma population in those $(5 \%-10 \%)$ who despite a period of extensive re-evaluation of diagnosis and management

cannot be controlled with a combination of high-dose inhaled corticosteroids together with LABAs.

Although no universally agreed definition exists, various labels, such as refractory asthma (Table 1$),{ }^{16}$ severe asthma, and therapy-resistant asthma, have all been ascribed to this aspect of asthma. Difficult-to-treat asthma may be characterized by poor symptom control, persistent airflow obstruction, and/or recurrent exacerbations, including fatal or near-fatal episodes, despite high medication requirements to maintain disease control, which itself too often complicates the illness. ${ }^{16}$ The concept of difficult-to-treat asthma is highlighted here because this group of patients is likely to be the group for which novel approaches, including specific targeted therapies, are likely to be particularly needed. In these patients, existing therapies either do not achieve adequate control or do so only at high doses, leading to unacceptable side effects. The lack of a consistent definition and the wide range of clinical presentations reflect the

Table I Refractory asthma: workshop consensus for typical clinical features*

\section{Major characteristics}

In order to achieve control to a level of mild to moderate persistent asthma:

I.Treatment with continuous or near-continuous ( $50 \%$ of year) oral corticosteroids

2. Requirement for treatment with high-dose inhaled corticosteroids

Drug

a. Beclomethasone dipropionate

c. Flunisolide

d. Fluticasone propionate

e. Triamcinolone acetonide $>2000$

Minor characteristics

I. Requirement for daily treatment with a controller medication in addition to inhaled corticosteroids, eg, long-acting $\beta$-agonist, theophylline, or leukotriene antagonist

2. Asthma symptoms requiring short-acting $\beta$-agonist use on a daily or near-daily basis

3. Persistent airway obstruction ( $\mathrm{FEV}_{1}<80 \%$ predicted; diurnal PEF variability $>20 \%$ )

4. One or more urgent care visits for asthma per year

5. Three or more oral steroid 'bursts' per year

6. Prompt deterioration with $25 \%$ reduction in oral or inhaled corticosteroid dose

7. Near-fatal asthma event in the past

Note: *Requires that other conditions have been excluded, exacerbating factors treated, and patient felt to be generally adherent.

Definition of refractory asthma requires one or both major criteria and two minor criteria. Copyright @ 2010, American Thoracic Society. Reproduced with permission from Proceedings of the ATS workshop on refractory asthma: current understanding, recommendations, and unanswered questions. American Thoracic Society. Am J Respir Crit Care Med. 2000;162(6):234I-235I. 
heterogeneous nature of asthma in general ${ }^{17,18}$ and difficultto-treat asthma in particular. ${ }^{1,2} \mathrm{~A}$ sound understanding of this heterogeneity is crucial for the successful development and appropriate utilization of new therapies for difficult-to-treat asthma and will now be discussed (see Table 1).

\section{Asthma heterogeneity and phenotyping}

Characterizing patients with asthma offers particular benefits in treating moderate to severe asthma providing not only prognostic information but also targeted therapeutic opportunities and helping to formulate a tailored approach to management. Historically, various methods of characterizing the heterogeneity of asthma have been considered based on specific features such as the age of onset, nature of airflow obstruction, pattern of exacerbations, or inflammatory profile. ${ }^{1,17,19}$ These systems of asthma classification are limited by inconsistency of method, subjective bias, and a failure to address the multiple dimensions of the disease, leading to models of little clinical significance. These limitations have led to increasing interest in more careful attempts at classification using multidimensional analytical techniques to identify specific asthma phenotypes.

We have recently described the results of a study using the technique of cluster analysis within a population of patients with severe asthma treated in our clinic compared with a second population managed in primary care. Cluster analysis is a multivariate statistical tool that seeks to organize information about variables so that heterogeneous groups of subjects can be classified into relatively homogeneous subgroups or 'clusters'. By including large numbers of variables, this approach may reveal associations that were not previously evident and lead to the identification of distinct novel phenotypes. Our results (Figure 1) identified two clusters (early-onset atopic asthma and obese, noneosinophilic asthma) that were common to both asthma populations. In contrast, two clusters characterized by marked discordance between symptom expression and eosinophilic airway inflammation (early-onset, symptom-predominant asthma and late-onset, inflammationpredominant asthma) were specific to refractory asthma. The identification of these separate phenotypes of asthma and in particular the recognition of the disparity between symptoms and inflammation highlight the need for the development of different management strategies for different groups of patients. A management strategy based on targeting airway inflammation may be particularly helpful for patients with inflammation-predominant asthma, ${ }^{15}$ for example, and will be discussed later. Further consideration of the complexity of the different aspects of airways disease has led to the recent suggestion that traditional labels applied to airways disease

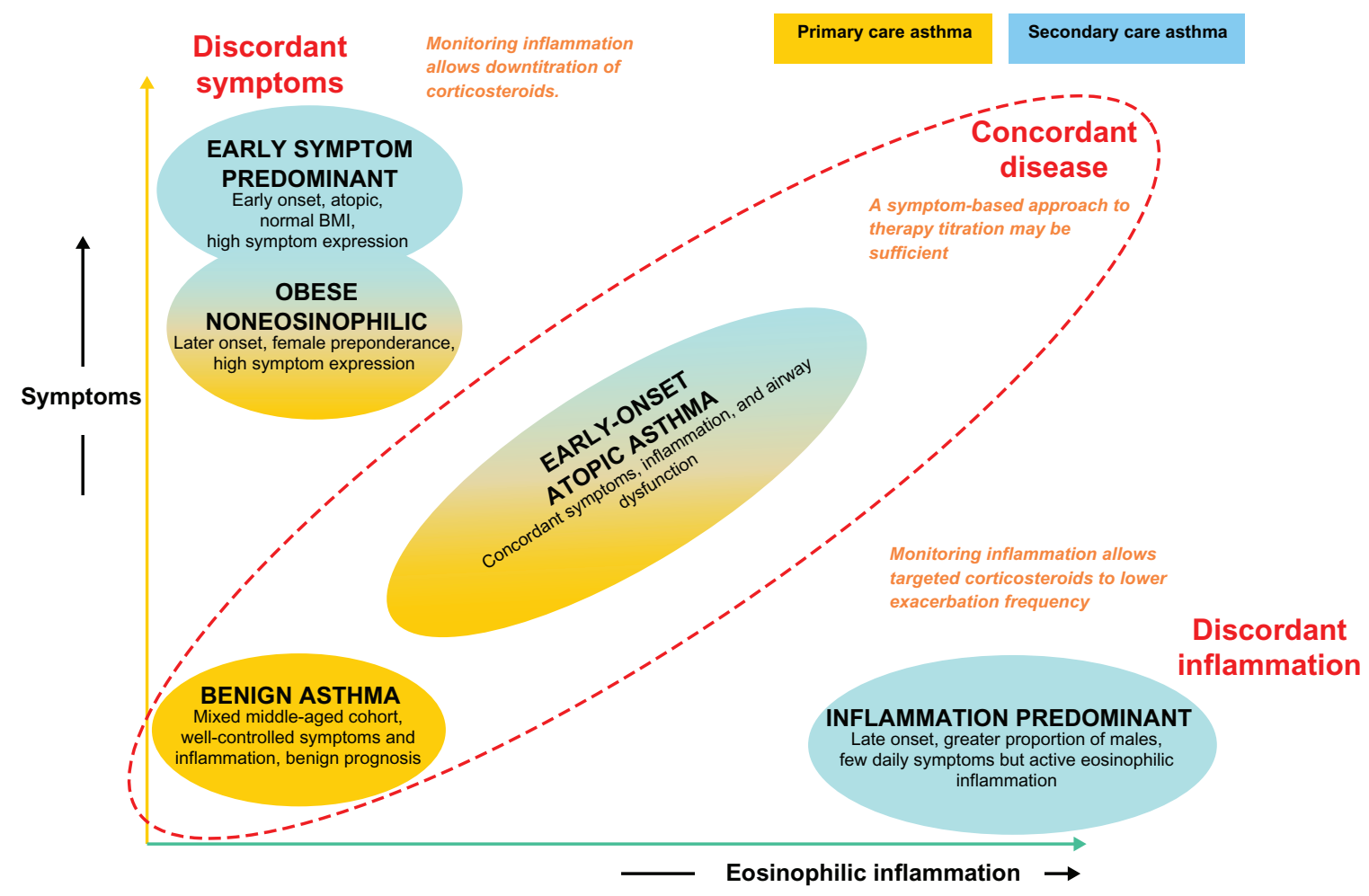

Figure I Clinical asthma phenotypes. Copyright (C 2010, American Thoracic Society. Reproduced with permission from Haldar P, Pavord ID, Shaw DE, et al. Cluster analysis and clinical asthma phenotypes. Am J Respir Crit Care Med. 2008;178(3):218-224. 
(including asthma and chronic obstructive pulmonary disease [COPD]) be replaced by an A to E alphabetical assessment tool using factors potentially responsible for morbidity: airway hyperresponsiveness, bronchitis, cough reflex hypersensitivity, and damage to the airway and surrounding lung, and extrapulmonary factors. ${ }^{20}$ This may offer a useful checklist to remind the clinician of the need to relate clinical presentation with underlying pathophysiology, and in doing so to select the most appropriate treatment strategy. For some patients, particularly those with difficult-to-treat asthma, this may be a novel pharmacological agent, whereas, for others, more judicious use of existing treatments may be sufficient to achieve good control.

\section{Improving the use of existing asthma therapies: patient-focused management strategies Self-management plans}

Patients with asthma deserve both oral and written advice helping them to recognize the signs of asthma and what to do when it is worsening.

With this in mind, one of the most significant advances in patient-focused developments in asthma therapy has been the way medications are employed. In particular, and in common with most chronic diseases, empowering patients to take responsibility through education is considered to be necessary to help patients gain the skills and confidence to control their asthma. A practical way of doing this is to provide patients with a written asthma selfmanagement or 'action' plan, an example of which is given in Table 2. This has seen distinct benefits both in economic

Table 2 Example of adult asthma self-management plan: what to do and when

\begin{tabular}{|c|c|c|c|}
\hline Step & Peak flow & Symptoms & Action \\
\hline I & $\begin{array}{l}80 \%-100 \% \\
\text { best }\end{array}$ & Intermittent/few & $\begin{array}{l}\text { Continue regular } \\
\text { inhaled corticosteroids; } \\
\text { use inhaled } \beta \text {-agonist } \\
\text { for relief of symptoms }\end{array}$ \\
\hline 2 & $\begin{array}{l}<80 \%-85 \% \\
\text { best }\end{array}$ & $\begin{array}{l}\text { Waking at night } \\
\text { with asthma; } \\
\text { increasing } \\
\beta \text {-agonist use }\end{array}$ & $\begin{array}{l}\text { Increase the dose of } \\
\text { inhaled corticosteroid } \\
\text { or start if not currently } \\
\text { taking }\end{array}$ \\
\hline 3 & $\begin{array}{l}<60 \%-70 \% \\
\text { best }\end{array}$ & $\begin{array}{l}\text { Beta-agonist use } \\
>2 \text { hourly; } \\
\text { increasing } \\
\text { breathlessness }\end{array}$ & $\begin{array}{l}\text { Start oral corticosteroids } \\
\text { and contact a doctor }\end{array}$ \\
\hline 4 & $<50 \%$ best & $\begin{array}{l}\text { Severe attack } \\
\text { of asthma; poor } \\
\text { response to } \\
\beta \text {-agonist }\end{array}$ & $\begin{array}{l}\text { Call emergency doctor } \\
\text { or ambulance urgently }\end{array}$ \\
\hline
\end{tabular}

terms and in reductions in morbidity in a recent Cochrane review. $^{21}$

It is well recognized that patients frequently fail to fully appreciate the severity of their asthma symptoms. ${ }^{22}$ Prior to most exacerbations is a period of deteriorating control usually seen 10-3 days prior to a more significant decline in symptom control. ${ }^{23}$ This pattern of escaping asthma control underwrites the utility of self-management plans, which, although based on an objective test such as peak flow measurements, often parallel a decline with symptoms of increasing wheeze and dyspnea. It allows patients, in particular those with concordant airway inflammation and symptoms, the prospect of recognizing escaping control and initiating early treatment with inhaled corticosteroids, rapidly suppressing airway inflammation that occurs during the evolution of an exacerbation, preventing its development, and thereby reducing mortality and morbidity by preventing hospital admissions. ${ }^{24}$

There is, however, a substantial variation in the structure and implementation of self-management plans, ${ }^{25}$ and factors facilitating their long-term use are not fully understood. ${ }^{26}$

\section{Stepwise incremental management}

Traditionally, inhaled therapies have been used in a symptomguided strategy, which remains the most widely accepted and practised strategy in optimizing asthma control. Although inhaled corticosteroids ${ }^{27}$ have been shown to be arguably the most important therapeutic and beneficial intervention in patients with airway disease, the importance of LABAs cannot be understated.

The Gaining Optimal Asthma Control (GOAL) ${ }^{10}$ study, one of the largest studies utilizing both combination and separate therapies, explored the potential of achieving total control of asthma symptoms. In this study, treatment was optimized in those with uncontrolled asthma symptoms, by increasing combination therapy at three monthly reviews until all asthma-related symptoms were abolished based on widely accepted guidelines.

Reconfirming earlier findings from similar trials of the importance of LABAs, ${ }^{28}$ it demonstrated that good control was achieved more rapidly by this strategy and at a lower corticosteroid dose with the fixed-dose inhaled corticosteroid and LABA combination product (seretide) than fluticasone alone despite total control not being achieved in the majority of patients (41\% versus $28 \%$, seretide versus fluticasone). Exacerbations occurred at much lower rates overall in this cohort $(<0.5$ mean exacerbations/patient/year in both groups), further 
suggesting that most of these patients had concordant disease appropriate for this symptom-driven type of management. Other phenotypes, however, run the potential risk of over- or undertreatment.

The advantage of combination therapy in being able to control asthma at lower doses of corticosteroids while reducing the total number of inhalers has since led to its widespread adoption in most management guidelines. There has been recent concern that though LABAs improve lung function and symptoms in asthma, their use may be associated with more severe symptoms and increased mortality ${ }^{29,30}$ during severe exacerbations of asthma. It is not clear, however, whether the link between LABAs and worsening asthma exacerbations is causal or rather whether the use of LABAs reflects more severe asthma or may reduce adherence to corticosteroids by improving symptoms without addressing underlying airway inflammation. Nevertheless, these concerns have led to a decision by the US Food and Drug Administration to issue a 'black box' ${ }^{31}$ warning to confine the use of LABAs to patients who remain poorly controlled despite inhaled corticosteroids and to recommend in pediatric and adolescent patients that LABAs should only be prescribed in a combination inhaler to ensure adherence to both medications.

\section{Single maintenance and reliever therapy}

Inherent in persistent asthma is the periodic need for reliever medication for symptoms that may invite overreliance on short-acting $\beta_{2}$-agonists at the expense of reduced adherence to inhaled corticosteroid therapy (ICS).

Formoterol, an LABA, uniquely offers both immediate (within 1-3 min) and sustained bronchodilation ${ }^{32}$ equivalent to salbutamol, allowing its use in combination preparations to be used in single maintenance and reliever therapy (SMART) recognized by international guidelines.

Although short-acting bronchodilators provide rapid relief of symptoms such as dyspnea associated with allergen-induced bronchoconstriction, they fail to address the accompanying eosinophilic inflammation known to precede exacerbations in asthma. ${ }^{33}$ One potential advantage of the SMART strategy is that patients will simultaneously receive additional doses of inhaled corticosteroids alongside a bronchodilator when they use their combined inhaler for symptom relief. This may target anti-inflammatory treatment to periods of poor control when it is most needed, aside from the convenience the strategy may give to patients.

The FACET study ${ }^{28}$ demonstrated that both budesonide and formoterol had complementary effects on reducing exacerbations in adults and provided greater improvements in symptoms at low doses. Pharmacologically, both budesonide and formoterol reduce the secretion of granulocytemacrophage colony-stimulating factor, counteracting the capacity of formoterol alone to induce interleukin-8 (IL-8) production, which may itself facilitate improved asthma control. ${ }^{34}$ Corticosteroids also promote increased expression of $\beta_{2}$-receptors through gene transcription, ${ }^{35,36}$ protecting against the loss of LABA response, which is essential when used in rescue therapy.

Several studies have consequently sought to demonstrate the added advantages of SMART over conventional maintenance therapy, though with mixed results. Exacerbations (the clinical endpoint of most comparison trials of SMART) have been significantly reduced when higher doses of ICS have been employed in the flexible dosing of budesonide/ formoterol therapy. O'Byrne et $\mathrm{al}^{37}$ showed that although patients on SMART averaged 50\% higher mean daily ICS doses than patients using traditional fixed combination therapy with short-acting $\beta_{2}$-agonists, they used significantly less ICS overall than those on higher-dose ICS alone. SMART also conferred at least a $45 \%$ reduction in severe exacerbations compared with other treatment arms. Other studies using similar combination therapies in fixed doses have found similar reductions in exacerbations. Bousquet et $\mathrm{al}^{38}$ in a study involving 2309 patients across 17 countries, compared the use of formoterol/budesonide as maintenance and reliever therapy with sustained highdose salmeterol/fluticasone. No significant difference in the primary endpoint of time to first exacerbations was seen, though there was a modest reduction in the total number of exacerbations again despite being on a lower dose of inhaled corticosteroid. A retrospective analysis of several studies of the use of SMART has raised concerns that this strategy fails to provide good day-to-day symptom control for the majority of patients ${ }^{39}$ in addition to the antiinflammatory mode of action being cast into doubt. ${ }^{40}$

Although not demonstrably improving asthma control above other combination therapies, it does allow patients a reduction in inhalers, which may play a helpful role in improving adherence, ${ }^{41}$ particularly in those who are poorly adherent to ICS. ${ }^{42}$

\section{Airway inflammometry}

The use of noninvasive biomarkers in monitoring airway inflammation has provided an alternative method to patientdriven symptom management for the assessment and management of asthma. 
Inflammometry ${ }^{43}$ provides a direct measure to identify the need for corticosteroids in relation to underlying airway inflammation, allowing judicious use of these agents to improve symptoms and reduce exacerbations and medication side effects. The use of nebulized hypertonic saline to induce sputum has provided a simple, safe, noninvasive airway sampling technique ${ }^{44}$ to assess airway inflammation and has now secured a place in managing patients with chronic cough ${ }^{45}$ and refractory asthma ${ }^{12,46,47}$ where it has shown particular benefit, though its use is still mainly limited to tertiary centers.

\section{Induced sputum eosinophil counts}

Healthy subjects usually have a sputum eosinophil count of $<1.9 \%$, but this is commonly elevated in up to $60 \%$ of patients with asthma. Additionally, infiltration of the airway mucosa with activated eosinophils is observed in postmortem examinations of patients who have died of acute severe asthma.$^{48}$ Early studies published in the Lancet in 1958 had shown the importance of an airway eosinophilia in predicting the clinical response to prednisolone with a reduction in eosinophils seen in sputum smears. ${ }^{49}$ The response to corticosteroids is further explained by the increased eosinophil apoptotic rate observed. ${ }^{50}$

A cutoff of 3\% for sputum eosinophilia has been shown to identify individuals with corticosteroid-responsive asthma ${ }^{51}$ and, utilizing this, $\mathrm{we}^{46}$ successfully demonstrated the benefits of a management strategy directed at normalizing eosinophilic airway inflammation over a standard symptom-based management strategy. This was based on the hypothesis that low sputum eosinophil counts would predict few exacerbations.

We randomized 74 attending outpatients with moderate to severe asthma into treatments based on standard guidelines (BTS) or to a management strategy directed at maintaining the sputum eosinophil count at or below 3\% using antiinflammatory therapy, both inhaled and oral. If the sputum eosinophil count was $<1 \%$, irrespective of asthma control, anti-inflammatory treatment was reduced. If the eosinophil count was $1 \%-3 \%$, no changes to anti-inflammatory treatment were made, and if the eosinophil count was $>3 \%$, anti-inflammatory treatment was increased. Bronchodilator treatment was modified according to individual patients' symptoms, rescue $\beta_{2}$-agonists use, and peak expiratory flow readings compared with baseline using the same measures as in the standard management group (Figure 2). There were significantly fewer severe exacerbations in the sputum management group in contrast to the BTS management group (35 versus 109 total exacerbations, respectively, $P=0.01$ ) and

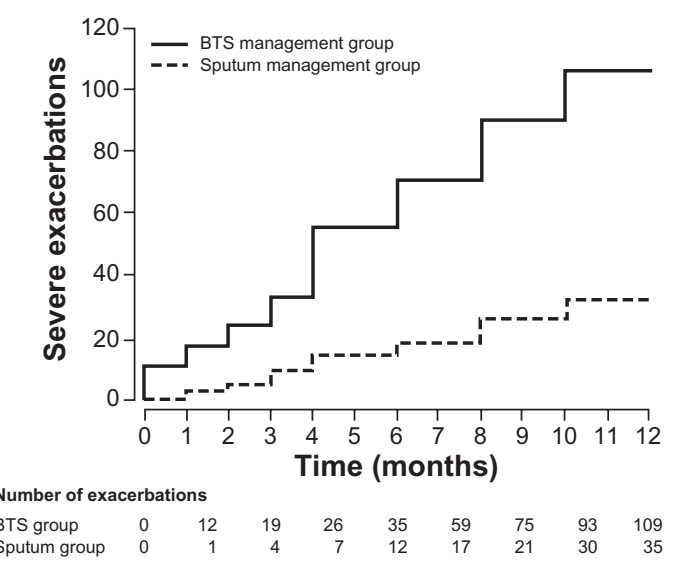

Figure 2 Cumulative asthma exacerbations in the BTS management group and the sputum management group.

Copyright @ 2010, Elsevier Limited. Reproduced with permission from Green RH, Brightling Ce, McKenna S, et al. Asthma exacerbations and sputum eosinophil counts: a randomised controlled trial. Lancet. 2002;360(9347):I7I5-I721.

fewer rescue courses of oral corticosteroids (24 versus 73, $P=0.008)$. Additionally, we demonstrated a significant reduction in the inhaled corticosteroid dose in those managed by sputum guidelines compared with baseline, in contrast to an increase in dose in the BTS group. This demonstrated that the sputum management strategy allowed appropriate targeting of anti-inflammatory treatment where it was most needed and an avoidance of inappropriately high doses in patients who were unlikely to benefit. Accepting that widespread inflammometry using induced sputum is not available, this tailored approach offers significant proven benefits to patients with severe asthma, particularly in avoiding harmful unwarranted treatment.

\section{Fraction of nitric oxide in exhaled air}

Alternative noninvasive measurements of airway inflammation have since been sought to offer supportive bedside measures easily and readily available outside of large hospitals or research centers. Against this background, with its reproducibility and noninvasive nature, the measurement of fraction of exhaled nitric oxide (FeNO), which is elevated in the presence of airway inflammation, has attracted interest furthered by its relationship, albeit loose, to sputum eosinophils. Although confounded by factors such as atopy ${ }^{52}$ and respiratory viral infections, ${ }^{53}$ and widely varying agreed cutoff values and confidence intervals (CIs), ${ }^{54,55} \mathrm{FeNO}$ appears to be a useful screening and management tool in asthma in defining lower airway pathology, being rarely present in nonasthmatics ${ }^{54,56}$ and lowered by use of corticosteroids. ${ }^{57}$

Two main trials in adults have evaluated the use of FeNO in conjunction with clinical parameters to titrate inhaled 
corticosteroid dose. Shaw et $\mathrm{al}^{58}$ recruited 128 patients from primary care, randomized them to two groups, and evaluated them over a 1-year period. ICS was adjusted according to FeNO levels, where above 26 parts/billion (ppb) it was increased and if it was $<16 \mathrm{ppb}$ or $<26 \mathrm{ppb}$ on two consecutive occasions, treatment was decreased. Additional bronchodilator therapy was used to control symptoms. No significant differences were observed between the two treatment arms. The FeNO management strategy resulted in 0.33 exacerbations/patient/year (0.69) in the FeNO group and $0.42(0.79)$ in the control group (mean difference $-21 \%$; 95\% CI: $-57 \%-43 \% ; P=0.43)$. The study did not, however, have sufficient power to demonstrate a more modest effect on exacerbation frequency.

Smith et $\mathrm{al}^{56}$ used FeNO in managing an ICS downtitration and compared it with conventional guidelines based on a protocol algorithm and an FeNO cutoff of 35 ppb equivalent. This also resulted in a $40 \%$ ICS dose reduction without change in the exacerbation frequency. Although results from these and other studies ${ }^{59}$ using different FeNO cutoff levels suggest a beneficial effect in using FeNO in managing asthma, it has yet been shown to improve asthma control. Moreover, trials in pediatric asthma populations included in a recent Cochrane review ${ }^{60}$ potentially resulted in higher doses of inhaled corticosteroids in children. Although FeNO has shown promise as a tool in the diagnosis and treatment of asthma, further studies incorporating individualized FeNO profiles into treatment algorithms are needed.

\section{The recognition and management of nonadherence}

Despite all the advances in expensive biological therapeutics, identifying nonadherence is of important diagnostic value in severe asthma. Worryingly, several studies have found that a significant proportion of patients with difficult asthma are poorly adherent to inhaled and oral corticosteroid therapy. Gamble et $\mathrm{al}^{61}$ found that $35 \%$ of patients collected less than half of their prescription, and $88 \%$ admitted poor adherence with inhaled therapy after initial denial. We have also shown that patients with severe asthma who adhere poorly to inhaled corticosteroids have worse asthma control and higher ITU admissions. ${ }^{62}$ Not infrequently, patients also forget or fail to understand proper inhaler technique, ${ }^{63}$ which should be demonstrated at least once and perhaps on repeated occasions, as adherence is learned behavior that can be improved with practice and reinforcement. Reasons for poor adherence are numerous, ${ }^{64,65}$ though strategies to prevent and correct nonadherence are difficult and there is no convincing evidence for their success in asthma. ${ }^{66}$ Suggested approaches are to improve patient education by targeted interventions, and there is some evidence to support the introduction of asthma self-management plans as already outlined in improving adherence. ${ }^{67}$ The use of combination inhalers as single inhaler therapy as described above is attractive, and there is some evidence to suggest that this approach may increase the likelihood of adherence to inhaled corticosteroids, ${ }^{42}$ although further work is needed to confirm this. Finally, for some patients with particularly severe asthma who are thought to be nonadherent to treatment and who are at risk of near-fatal attacks, we and others have used short courses of intramuscular triamcinolone to demonstrate a good steroid response and exclude true corticosteroid resistance. ${ }^{4}$ Improvement in asthma control following systemic corticosteroids in this way may increase patients' awareness of their poor asthma control and motivate them to start taking their treatment regularly to maintain improvements in their symptoms. ${ }^{4,68,69}$

\section{Novel therapeutic options}

Despite effectively reducing exacerbations, systemic corticosteroids have significant adverse effects in asthma that prohibit their long-term use and have driven the search for alternative therapies with acceptable risk-to-benefit ratios not achievable with commonly used immunosuppressants such as methotrexate, azathioprine, gold, or cyclosporine. ${ }^{63}$

Much recent work has therefore been concerned with the introduction of novel therapies targeting specific components of the anti-inflammatory pathway usually via a systemic approach. These include monoclonal antibodies (mAbs) targeting IgE, tumor necrosis factor-alpha (TNF- $\alpha$ ) or IL-5, and thermal bronchoplasty and antifungal agents. In view of their invasive nature, risk of adverse effects, and expense, these treatments are likely to have narrow, well-defined roles in asthma management and will usually be reserved for patients with difficult-to-treat asthma. The evidence supporting their use will now be discussed.

\section{Anti-lgE therapy}

Allergens are one of the many multiple triggers in asthma, ${ }^{70}$ and through their tendency for $\mathrm{IgE}$ production give rise to airway inflammation, which is an important aspect of allergic asthma and exacerbations.

The first of the European Community Respiratory Health Surveys, a cross-sectional, multicenter study, identified the rates of atopy as defined by an elevated specific $\operatorname{IgE}$ to common aeroallergens as varying from $4 \%$ to $61 \%$, depending on the country examined. ${ }^{71}$ 
The IgE receptor FceRI is significantly upregulated on eosinophils, mast cells, macrophages, and dendritic cells in patients with rhinitis and allergic asthma. Mast cell activation through IgE releases a variety of proinflammatory cytokines including IL-4, IL-13, and IL-5 all contributing to the inflammatory and bronchoconstrictive response seen in asthma.

Omalizumab, a recombinant humanized monoclonal antibody, is the first treatment to specifically bind $\operatorname{IgE}$ and block its effects. It targets the $\mathrm{Fc}$ region that attaches to the high-affinity receptor FceRI, binding free IgE, significantly reducing circulating free IgE levels, and downregulating the receptor.

In a 28 -week, randomized, placebo-controlled trial, the Investigation of Omalizumab in Severe Asthma Treatment (INNOVATE) study ${ }^{72}$ demonstrated the efficacy of omalizumab in those with severe persistent allergic asthma as add-on therapy, showing significant improvements in quality of life across all domains and a $26 \%$ reduction in exacerbation rates when corrected for baseline exacerbations compared with placebo $(P=0.002)$.

Earlier studies in patients with sputum eosinophilia elucidated their mechanisms of action in the depletion of $\operatorname{IgE}$ from airway tissue with marked reductions in airway eosinophilia as measured by sputum and bronchial biopsies. ${ }^{73}$

Patients with recurrent exacerbations appear to benefit most from this treatment. A recent Cochrane review ${ }^{74}$ concluded highly significant reductions in frequency and duration of exacerbations, including a $90 \%$ reduction in hospitalization, together with a reduction in the use of both inhaled steroids and rescue drugs. Compliance issues are also minimized with its administration as $2-4$ weekly subcutaneous injections with the dose based on the patients' serum total IgE level and body weight.

Omalizumab treatment is generally well tolerated with few adverse effects, although anaphylaxis attributed to its administration has been quoted as being between $0.1 \%$ and $0.2 \%$ in clinical trials and postmarketing survelliance. ${ }^{75}$ In addition, clinical trial data suggest that, numerically, more malignancies were reported in patients receiving omalizumab compared with control $(0.5 \%$ versus $0.2 \%)$. This difference was not statistically significant, but the long-term risk of additional malignancies is unknown. The major limitation to the use of omalizumab is its cost, which restricts its use in patients with severe atopic uncontrolled asthma despite adequate doses of inhaled corticosteroids and LABAs who demonstrate persistent symptoms and a degree of airflow obstruction and who are sensitized to a perennial allergen. In addition, patients' total IgE levels should be in the range of 30-1500 IU/mL, and some patients will have a total IgE greater than the maximum recommended for dosing in relation to their body weight. A recent audit in our clinic showed that only 34 out of 251 patients with difficultto-control asthma were eligible for treatment based on these licensing criteria. ${ }^{76}$ Furthermore, in the UK, guidance from the National Institute for Health and Clinical Excellence now limits its prescription to patients who meet the licensing criteria and who have also had two or more hospital admissions or one admission plus two A\&E attendances for asthma exacerbations. Using these additional criteria, only $6.2 \%$ of our patients were eligible for treatment with omalizumab. Nevertheless, if funding is available, this does appear to be a promising therapy for patients with severe atopic disease and may be particularly helpful to patients who have additional atopic diseases alongside asthma, such as severe rhinitis. ${ }^{77}$

\section{Antitumor necrosis factor- $\alpha$ therapy}

In patients with rheumatoid arthritis, TNF- $\alpha$, with its ability to promote inflammation, is markedly increased in the synovial fluid, and treatment with TNF- $\alpha$ mAbs has resulted in substantial improvement in disease activity scores. ${ }^{78}$ Both macrophage and mast cells release TNF- $\alpha$ in allergic responses via IgE-dependent mechanisms ${ }^{79}$ and can also induce its own production via an autocrine mechanism. The TNF- $\alpha$ axis is found to be upregulated in patients with severe asthma ${ }^{80,81}$ and is consequently thought to play a key role in the pathogenesis of inflammatory disorders. This recognition has led to trials of anti-TNF- $\alpha$ therapy in patients with asthma. Despite initially promising results, subsequent studies have not only shown a marked heterogeneous response, suggesting benefit to a small subgroup, but also highlighted concerns about its safety.

Using the most widely studied anti-TNF agent in asthma, etanercept, Berry et al ${ }^{80}$ demonstrated significant improvements in airways hyperresponsiveness and quality of life and reduced expression of membrane-bound TNF- $\alpha$ by peripheral blood monocytes in patients with refractory asthma treated for 10 weeks. Morjaria et $a^{12}$ found small but similar significant improvements in patients' asthma control questionnaire responses but failed to replicate other earlier findings in an unselected refractory asthma population. The largest and longest study to date, using golimumab for 52 weeks and involving 231 patients, found no benefit compared with placebo. ${ }^{83}$

Unfortunately, anti-TNF antibody agents may increase the risk of serious infections and malignancies in patients with 
rheumatoid arthritis, ${ }^{84}$ though larger, more carefully selected studies may be required before this therapy is abandoned.

\section{Anti-IL-5 therapy}

IL-5 has long been regarded as an important cytokine responsible for eosinophil differentiation, maturation, migration, and survival. mAbs directed against this cytokine offering the prospect of abolishing exacerbations without entertaining the significant problems associated with corticosteroid therapy seemed possible.

The initial enthusiasm for anti-IL-5 was, however, tampered by the apparent failure of eosinophilic suppression through anti-IL-5 to confer clinical benefit in the asthmatic late response. Leckie et al ${ }^{85}$ showed that anti-IL-5 blockade effectively suppressed blood and sputum eosinophilia in the mild asthmatic cohort, but in studying airway hyperresponsiveness as an outcome failed to appreciate that these measures are not closely associated with eosinophilic airway inflammation. This suggests that the choice of an alternative outcome measure may have demonstrated significant patient benefits. The demonstration that a sputum and bronchial submucosal eosinophilia occurs in eosinophilic bronchitis, a condition that presents with chronic cough without airway hyperresponsiveness ${ }^{86}$ further supports this view, as did earlier studies demonstrating significant reductions in eosinophilic exacerbations using management strategies that control airway inflammation. ${ }^{46}$

In a double-blind, placebo-controlled trial, the largest to date, involving patients with refractory asthma and eosinophilic inflammatory phenotypes, we have shown the profound effect of mepolizumab on suppressing both blood and sputum eosinophils. ${ }^{87}$ This effect consequently reduced asthma exacerbations significantly, with a reduction in episodes requiring high-dose oral corticosteroids ( 2 versus 3.4 exacerbations/subject/year; $P=0.02$ ) as well as improved quality of life. There were no improvements in symptoms or forced expiratory volume in 1 second consistent with previous studies ${ }^{88}$ further illustrating the disassociation between eosinophilic airway inflammation and day-to-day symptoms and lung function while confirming the increased risk of exacerbations seen alongside uncontrolled airway eosinophilia. Nair et a ${ }^{89}$ also evaluated a similar steroiddependant cohort involving 20 patients; 9 were treated with mepolizumab $750 \mathrm{mg}$ administered over 5 monthly infusions and 11 patients received placebo. Again, the mepolizumab group experienced a significant decrease in asthma exacerbations and were able to reduce their prednisolone dose significantly.
Further work is ongoing with the larger multicenter study Dose Ranging Efficacy and Safety with Mepolizumab in Severe Asthma (DREAM) ${ }^{90}$ underway, but the likely role for this treatment will be in a selected group. Importantly, characterizing patients with inflammometry provides targeted treatment and is likely to be particularly helpful in selecting patients for treatment with anti-iL-5, because those patients with inflammation-predominant disease are particularly likely to benefit.

\section{Antifungal therapy}

With up to $60 \%$ of patients with asthma being atopic to common aeroallergens, sensitization to fungi appears to be an emerging phenotype conferring an increased risk of hospital and ITU admissions. ${ }^{91}$ Exposure to allergenic fungi is ubiquitous in the aerospora, which we have shown to be present in sputum from colonized airways of patients with asthma, ${ }^{92}$ further increasing the body of evidence about the link between fungal sensitization and severe asthma. ${ }^{93}$

Several trials in patients with allergic bronchopulmonary aspergillosis ${ }^{94}$ have established the role of antifungal therapy, but only recently have trials in asthma been undertaken. The Fungal Asthma Sensitization Trial (FAST) ${ }^{95}$ studied patients with severe asthma who were sensitized by a skin prick or radioallergosorbent testing to one or more fungal allergens and did not fulfill the criteria for allergic bronchopulmonary mycosis. Treatment with oral itraconazole $200 \mathrm{mg}$ twice daily/placebo for 32 weeks resulted in clinically significant improvements of asthma quality of life scores as well as rhinitis and morning peak flows.

Interestingly, the precise mechanisms of antifungal action in asthma remain unknown. Although generally accepted to modulate the immunological response, concerns remain about the azole-corticosteroid interaction as seen in earlier trials with adrenal suppression. ${ }^{94}$ Although active against some species of Aspergillus, itraconazole is not active against all of the fungal species that the human airway is constantly subjected to. Its microbiological activity is further limited by variable absorption and need for monitoring ${ }^{96}$ in contrast to newer triazoles that have better oral bioavailability. Further trials in this interesting area are warranted.

\section{Thermal bronchoplasty}

Targeted treatment of the airway smooth muscle hypertrophy seen in chronic asthma, aside from other changes of airway remodeling including goblet cell hyperplasia, increased mucus secretion, and increased vascularization, has been made possible with a novel technique utilizing radiofrequency 
ablation. Treatment involves delivering thermal energy through use of a standard bronchoscope into which a catheter containing an expandable basket is inserted. When extended, this comes into circumferential contact with the walls of targeted airways, thus depleting smooth muscle mass with the hope of attenuating the bronchoconstrictor response.

In clinical studies, thermal bronchoplasty has been shown to reduce parameters of airways hyperresponsiveness and minimize exacerbations. The randomized, double-blind, shamcontrolled AIR 2 study ${ }^{97}$ built on earlier promising results ${ }^{98}$ and demonstrated a clinically significant improvement in asthma quality of life in up to $80 \%$ of patients over those treated with the sham protocol, as well as a $36 \%$ reduction in exacerbations with benefits persisting at 1 year.

The benefits were overshadowed early on, however, with a higher rate of exacerbations in the treatment arm up to 6 weeks after therapy ( $6 \%$ more than placebo). All other adverse events were not significantly different. These exacerbations required hospital admissions and steroids, which may have confounded the improved asthma control seen later on. More important was the profound placebo effect, with $64 \%$ of sham subjects achieving changes in Asthma Quality of Life Questionnaire of 0.5 or greater.

This procedure offers a novel way to reduce the expression of smooth muscle in patients not controlled with combinations of anti-inflammatory and bronchodilators. This suggests that its greatest potential is in the long-lasting duration of effect in contrast to other therapies, but longer follow-up studies are required to evaluate this.

\section{Conclusion}

Treatments for asthma are rapidly evolving with the development of both novel pharmacological therapies and the establishment of new management strategies with which to deploy existing therapies. With these developments has come the recognition that previous goals of therapy can be improved to focus not only on preventing death and severe exacerbations but also on improving day-to-day symptom control and quality of life. Individual treatments and management strategies in general are likely to be most successful where they offer convenience for patients and/or aid adherence. Many of these patient-focused strategies are readily available. Although sputum cell analysis had previously been limited as a research tool, it is gradually gaining widespread acceptance as an invaluable biomarker in clinical practice in concert with the developments in bedside inflammometry using FeNO.

Although novel biological therapies offer a useful adjunct for those patients who are unresponsive to conventional treatment, the varied responses to these agents emphasize the need for careful patient selection. This highlights the vital importance of accurate phenotyping of the asthma population not only to ensure that each individual patient receives the most appropriate therapy but also to maximize the likelihood of the successful development of additional new drugs.

\section{Disclosure}

The authors report no conflicts of interest in this work.

\section{References}

1. McFadden ER Jr. A century of asthma. Am J Respir Crit Care Med. 2004;170(3):215-221.

2. Wardlaw AJ, Brightling C, Green R, Woltmann G, Pavord I. Eosinophils in asthma and other allergic diseases. Br Med Bull. 2000;56(4): 985-1003.

3. Djukanovic R, Homeyard S, Gratziou C, et al. The effect of treatment with oral corticosteroids on asthma symptoms and airway inflammation. Am J Respir Crit Care Med. 1997;155(3):826-832.

4. ten Brinke A, Zwinderman AH, Sterk PJ, Rabe KF, Bel EH. "Refractory" eosinophilic airway inflammation in severe asthma: effect of parenteral corticosteroids. Am J Respir Crit Care Med. 2004;170(6):601-605.

5. O’Byrne PM, Pedersen S, Lamm CJ, Tan WC, Busse WW. Severe exacerbations and decline in lung function in asthma. Am J Respir Crit Care Med. 2009;179(1):19-24.

6. Bousquet J, Bousquet PJ, Godard P, Daures JP. The public health implications of asthma. Bull World Health Organ. 2005;83(7):548-554.

7. Asthma UK. High cost of asthma in West Midlands. Available from: http://www.asthma.org.uk/news_media/media_releases/high_cost_of_ asthm_3.html. Updated 2009 Oct 22.

8. Godard P, Chanez P, Siraudin L, Nicoloyannis N, Duru G. Costs of asthma are correlated with severity: a 1-yr prospective study. Eur Respir J. 2001;19(1):61-67.

9. Serra-Batlles J, Plaza V, Morejon E, Comella A, Brugues J. Costs of asthma according to the degree of severity. Eur Respir J. 1998;12(6): $1322-1326$.

10. Bateman ED, Boushey HA, Bousquet J, et al. Can guideline-defined asthma control be achieved? The Gaining Optimal Asthma Control study. Am J Respir Crit Care Med. 2004;170(8):836-844.

11. Rabe KF, Vermeire PA, Soriano JB, Maier WC. Clinical management of asthma in 1999: the Asthma Insights and Reality in Europe (AIRE) study. Eur Respir J. 2000;16(5):802-807.

12. SIGN and the British Thoracic Society (BTS). British Guideline on the Management of Asthma. Edinburgh (UK): SIGN and the British Thoracic Society (BTS); 2010. Guideline No. 101, ISBN 978190581 28 5, 2008 May, Revised 2009 Jun.

13. Reddel HK, Taylor DR, Bateman ED, et al. An official American Thoracic Society/European Respiratory Society statement: asthma control and exacerbations: standardizing endpoints for clinical asthma trials and clinical practice. Am J Respir Crit Care Med. 2009;180(1):59-99.

14. Global Initiative for Asthma (GINA), National Heart Lung and Blood Institute (NHLBI). Global Strategy for Asthma Management and Prevention. Bethesda (MD): Global Initiative for Asthma (GINA), National Heart, Lung and Blood Institute (NHLBI); Available from: http://www.ginasthma.com. Updated 2010 Jan 12.

15. Haldar P, Pavord ID, Shaw DE, et al. Cluster analysis and clinical asthma phenotypes. Am J Respir Crit Care Med. 2008;178(3):218-224.

16. Proceedings of the ATS workshop on refractory asthma: current understanding, recommendations, and unanswered questions. American Thoracic Society. Am J Respir Crit Care Med. 2000;162(6):2341-2351.

17. Green RH, Brightling CE, Bradding P. The reclassification of asthma based on subphenotypes. Curr Opin Allergy Clin Immunol. 2007; 7(1): 43-50. 
18. Bradding P, Green RH. Subclinical phenotypes of asthma. Curr Opin Allergy Clin Immunol. 2010;10(1):54-59.

19. Wenzel SE. Asthma: defining of the persistent adult phenotypes. Lancet. 2006;368(9537):804-813.

20. Pavord ID, Wardlaw AJ. The A to E of airway disease. Clin Exp Allergy. 2010;40(1):62-67.

21. Gibson PG, Powell H, Wilson AJ, et al. Self-management education and regular practitioner review for adults with asthma. Cochrane Database Syst Rev. 2003(3):CD001117.

22. Kendrick AH, Higgs CM, Whitfield MJ, Laszlo G. Accuracy of perception of severity of asthma: patients treated in general practice. $B M J$. 1993;307(6901):422-424.

23. Tattersfield AE, Postma DS, Barnes PJ, et al. Exacerbations of asthma: a descriptive study of 425 severe exacerbations. The FACET International Study Group. Am J Respir Crit Care Med. 1999;160(2):594-599.

24. Abramson MJ, Bailey MJ, Couper FJ, et al. Are asthma medications and management related to deaths from asthma? Am J Respir Crit Care Med. 2001;163(1):12-18.

25. Holt S, Masoli M, Beasley R. The use of the self-management plan system of care in adult asthma. Prim Care Respir J. 2004;13(1):19-27.

26. Ring N, Malcolm C, Wyke S, et al. Promoting the use of personal asthma action plans: a systematic review. Prim Care Respir J. 2007;16(5): 271-283.

27. Haahtela T, Jarvinen M, Kava T, et al. Comparison of a beta 2-agonist, terbutaline, with an inhaled corticosteroid, budesonide, in newly detected asthma. N Engl J Med. 1991;325(6):388-392.

28. Pauwels RA, Lofdahl CG, Postma DS, et al. Effect of inhaled formoterol and budesonide on exacerbations of asthma. Formoterol and Corticosteroids Establishing Therapy (FACET). N Engl J Med. 1997;337(20): 1405-1411.

29. Nelson HS, Weiss ST, Bleecker ER, Yancey SW, Dorinsky PM. The Salmeterol Multicenter Asthma Research Trial: a comparison of usual pharmacotherapy for asthma or usual pharmacotherapy plus salmeterol. Chest. 2006;129(1):15-26.

30. Weatherall M, Wijesinghe M, Perrin K, Harwood M, Beasley R. Meta-analysis of the risk of mortality with salmeterol and the effect of concomitant inhaled corticosteroid therapy. Thorax. 2010;65(1): $39-43$.

31. US Food and Drug Administration, FDA. Long-Acting Beta-Agonists (LABAs): New Safe Use Requirements. Silver Spring (MD): FDA. Available from: http://www.fda.gov/Safety/MedWatch/SafetyInformation/SafetyAlertsforHumanMedicalProducts/ucm201003.htm. Accessed 2010 Oct 22.

32. van Noord JA, Smeets JJ, Raaijmakers JA, Bommer AM, Maesen FP. Salmeterol versus formoterol in patients with moderately severe asthma: onset and duration of action. Eur Respir J. 1996;9(8):1684-1688.

33. Jatakanon A, Lim S, Barnes PJ. Changes in sputum eosinophils predict loss of asthma control. Am J Respir Crit Care Med. 2000;161(1): 64-72.

34. Korn SH, Jerre A, Brattsand R. Effects of formoterol and budesonide on GM-CSF and IL-8 secretion by triggered human bronchial epithelial cells. Eur Respir J. 2001;17(6):1070-1077.

35. Baraniuk JN, Ali M, Brody D, et al. Glucocorticoids induce beta2adrenergic receptor function in human nasal mucosa. Am J Respir Crit Care Med. 1997;155(2):704-710.

36. Mak JC, Nishikawa M, Barnes PJ. Glucocorticosteroids increase beta 2-adrenergic receptor transcription in human lung. Am J Physiol. 1995; 268(1 Pt 1):L41-L46.

37. O'Byrne PM, Bisgaard H, Godard PP, et al. Budesonide/formoterol combination therapy as both maintenance and reliever medication in asthma. Am J Respir Crit Care Med. 2005;171(2):129-136.

38. Bousquet J, Boulet LP, Peters MJ, et al. Budesonide/formoterol for maintenance and relief in uncontrolled asthma vs high-dose salmeterol/ fluticasone. Respir Med. 2007;101(12):2437-2446.

39. Bateman ED, Reddel HK, Eriksson G, et al. Overall asthma control: the relationship between current control and future risk. J Allergy Clin Immunol. 2010;125(3):600-608.
40. Pavord ID, Jeffery PK, Qiu Y, et al. Airway inflammation in patients with asthma with high-fixed or low-fixed plus as-needed budesonide/ formoterol. J Allergy Clin Immunol. 2009;123(5):1083-1089.

41. Bosley CM, Parry DT, Cochrane GM. Patient compliance with inhaled medication: does combining beta-agonists with corticosteroids improve compliance? Eur Respir J. 1994;7(3):504-509.

42. Sovani MP, Whale CI, Oborne J, et al. Poor adherence with inhaled corticosteroids for asthma: can using a single inhaler containing budesonide and formoterol help? Br J Gen Pract. 2008;58(546):37-43.

43. Pavord ID, Shaw DE, Gibson PG, Taylor DR. Inflammometry to assess airway diseases. Lancet. 2008;372(9643):1017-1019.

44. Pavord ID, Pizzichini MM, Pizzichini E, Hargreave FE. The use of induced sputum to investigate airway inflammation. Thorax. 1997; 52(6):498-501.

45. Brightling CE, Ward R, Goh KL, Wardlaw AJ, Pavord ID. Eosinophilic bronchitis is an important cause of chronic cough. Am J Respir Crit Care Med. 1999;160(2):406-410.

46. Green RH, Brightling CE, McKenna S, et al. Asthma exacerbations and sputum eosinophil counts: a randomised controlled trial. Lancet. 2002;360(9347):1715-1721.

47. Jayaram L, Pizzichini MM, Cook RJ, et al. Determining asthma treatment by monitoring sputum cell counts: effect on exacerbations. Eur Respir J. 2006;27(3):483-494.

48. Houston JC, de Navasquez S, Trounce JR. A clinical and pathological study of fatal cases of status asthmaticus. Thorax. 1953;8(3): 207-213.

49. Brown HM. Treatment of chronic asthma with prednisolone; significance of eosinophils in the sputum. Lancet. 1958;2(7059):1245-1247.

50. Kankaanranta H, Lindsay MA, Giembycz MA, Zhang X, Moilanen E, Barnes PJ. Delayed eosinophil apoptosis in asthma. J Allergy Clin Immunol. 2000;106(1):77-83.

51. Hunter CJ, Brightling CE, Woltmann G, Wardlaw AJ, Pavord ID. A comparison of the validity of different diagnostic tests in adults with asthma. Chest. 2002;121(4):1051-1057.

52. Franklin PJ, Taplin R, Stick SM. A community study of exhaled nitric oxide in healthy children. Am J Respir Crit Care Med. 1999;159(1): 69-73.

53. Kharitonov SA, Yates D, Barnes PJ. Increased nitric oxide in exhaled air of normal human subjects with upper respiratory tract infections. Eur Respir J. 1995;8(2):295-297.

54. Malmberg LP, Pelkonen AS, Haahtela T, Turpeinen M. Exhaled nitric oxide rather than lung function distinguishes preschool children with probable asthma. Thorax. 2003;58(6):494-499.

55. Olin AC, Bake B, Toren K. Fraction of exhaled nitric oxide at $50 \mathrm{~mL} / \mathrm{s}$ : reference values for adult lifelong never-smokers. Chest. 2007;131(6): $1852-1856$.

56. Smith AD, Cowan JO, Filsell S, et al. Diagnosing asthma: comparisons between exhaled nitric oxide measurements and conventional tests. $\mathrm{Am}$ J Respir Crit Care Med. 2004;169(4):473-478.

57. Kharitonov SA, Yates D, Robbins RA, Logan-Sinclair R, Shinebourne EA, Barnes PJ. Increased nitric oxide in exhaled air of asthmatic patients. Lancet. 1994;343(8890):133-135.

58. Shaw DE, Berry MA, Thomas M, et al. The use of exhaled nitric oxide to guide asthma management: a randomized controlled trial. Am J Respir Crit Care Med. 2007;176(3):231-237.

59. de Jongste JC, Carraro S, Hop WC, Baraldi E. Daily telemonitoring of exhaled nitric oxide and symptoms in the treatment of childhood asthma. Am J Respir Crit Care Med. 2009;179(2):93-97.

60. Petsky HL, Cates CJ, Li A, Kynaston JA, Turner C, Chang AB. Tailored interventions based on exhaled nitric oxide versus clinical symptoms for asthma in children and adults. Cochrane Database Syst Rev. 2009;(4):CD006340.

61. Gamble J, Stevenson M, McClean E, Heaney LG. The prevalence of nonadherence in difficult asthma. Am J Respir Crit Care Med. 2009;180(9):817-822.

62. Murphy A, Proeschel A, Linnett ME, Bradding P, Green RH. Oral abstract sessions. Allergy. 2010;65:1-77. 
63. Leung DY, Bloom JW. Update on glucocorticoid action and resistance. J Allergy Clin Immunol. 2003;111(1):3-22.

64. van der Palen J, Klein JJ, van Herwaarden CL, Zielhuis GA, Seydel ER. Multiple inhalers confuse asthma patients. Eur Respir J. 1999;14(5): 1034-1037.

65. Boulet LP. Perception of the role and potential side effects of inhaled corticosteroids among asthmatic patients. Chest. 1998;113(3):587-592.

66. Bender B, Milgrom H, R and C. Nonadherence in asthmatic patients: is there a solution to the problem? Ann Allergy Asthma Immunol. 1997;79(3):177-185; quiz 185-186.

67. Janson SL, McGrath KW, Covington JK, Cheng SC, Boushey HA. Individualized asthma self-management improves medication adherence and markers of asthma control. J Allergy Clin Immunol. 2009;123(4): 840-846.

68. Mash B, Bheekie A, Jones PW. Inhaled vs oral steroids for adults with chronic asthma. Cochrane Database Syst Rev. 2001;(1):CD002160.

69. McGivney SA, Ogirala RG. Effect of high-dose intramuscular triamcinolone in older adults with severe, chronic asthma. Lung. 1994;172(2): 73-78.

70. Wardlaw AJ, Silverman M, Siva R, Pavord ID, Green R. Multidimensional phenotyping: towards a new taxonomy for airway disease. Clin Exp Allergy. 2005;35(10):1254-1262.

71. Sunyer J, Jarvis D, Pekkanen J, et al. Geographic variations in the effect of atopy on asthma in the European Community Respiratory Health Study. J Allergy Clin Immunol. 2004;114(5):1033-1039.

72. Humbert M, Beasley R, Ayres J, et al. Benefits of omalizumab as add-on therapy in patients with severe persistent asthma who are inadequately controlled despite best available therapy (GINA 2002 step 4 treatment): INNOVATE. Allergy. 2005;60(3):309-316.

73. Djukanovic R, Wilson SJ, Kraft M, et al. Effects of treatment with antiimmunoglobulin $\mathrm{E}$ antibody omalizumab on airway inflammation in allergic asthma. Am J Respir Crit Care Med. 2004;170(6):583-593.

74. Walker S, Monteil M, Phelan K, Lasserson TJ, Walters EH. Anti-IgE for chronic asthma in adults and children. Cochrane Database Syst Rev. 2006;(2):CD003559.

75. Genentech, Inc. Xolair(R) (omalizumab for subcutaneous use) package insert. South San Francisco, CA, 2003.

76. Hargadon B, Haldar P, Shaw D, et al. Eligibility for treatment with omalizumab among patients attending the Glenfield Hospital Refractory Asthma Clinic. Thorax. 2006;61 Suppl 2:ii57-ii133.

77. Adelroth E, Rak S, Haahtela T, et al. Recombinant humanized mAb-E25, an anti-IgE $\mathrm{mAb}$, in birch pollen-induced seasonal allergic rhinitis. J Allergy Clin Immunol. 2000;106(2):253-259.

78. Epstein FH, Choy EHS, Panayi GS. Cytokine pathways and joint inflammation in rheumatoid arthritis. N Engl J Med. 2009;344(12):907-916.

79. Ohkawara Y, Yamauchi K, Tanno Y, et al. Human lung mast cells and pulmonary macrophages produce tumor necrosis factor-alpha in sensitized lung tissue after IgE receptor triggering. Am J Respir Cell Mol Biol. 1992;7(4):385-392.

80. Berry MA, Hargadon B, Shelley M, et al. Evidence of a role of tumor necrosis factor $\alpha$ in refractory asthma. $N$ Engl J Med. 2009;354(7): 697-708.

81. Howarth PH, Babu KS, Arshad HS, et al. Tumour necrosis factor (TNFalpha) as a novel therapeutic target in symptomatic corticosteroid dependent asthma. Thorax. 2005;60(12):1012-1018.
82. Morjaria JB, Chauhan AJ, Babu KS, Polosa R, Davies DE, Holgate ST. The role of a soluble TNFalpha receptor fusion protein (etanercept) in corticosteroid refractory asthma: a double blind, randomised, placebo controlled trial. Thorax. 2008;63(7):584-591.

83. Wenzel SE, Barnes PJ, Bleecker ER, et al. A randomized, double-blind, placebo-controlled study of tumor necrosis factor-alpha blockade in severe persistent asthma. Am J Respir Crit Care Med. 2009;179(7): 549-558.

84. Bongartz T, Sutton AJ, Sweeting MJ, Buchan I, Matteson EL, Montori V. Anti-TNF antibody therapy in rheumatoid arthritis and the risk of serious infections and malignancies: systematic review and meta-analysis of rare harmful effects in randomized controlled trials. JAMA. 2006;295(19):2275-2285.

85. Leckie MJ, ten Brinke A, Khan J, et al. Effects of an interleukin-5 blocking monoclonal antibody on eosinophils, airway hyper-responsiveness, and the late asthmatic response. Lancet. 2000;356(9248):2144-2148.

86. Gibson PG, Dolovich J, Denburg J, Ramsdale EH, Hargreave FE. Chronic cough: eosinophilic bronchitis without asthma. Lancet. 1989; 1(8651):1346-1348.

87. Haldar P, Brightling CE, Hargadon B, et al. Mepolizumab and exacerbations of refractory eosinophilic asthma. $N$ Engl J Med. 2009; 360(10):973-984.

88. Flood-Page P, Swenson C, Faiferman I, et al. A study to evaluate safety and efficacy of mepolizumab in patients with moderate persistent asthma. Am J Respir Crit Care Med. 2007;176(11):1062-1071.

89. Nair P, Pizzichini MM, Kjarsgaard M, et al. Mepolizumab for prednisone-dependent asthma with sputum eosinophilia. NEngl J Med. 2009; 360(10):985-993.

90. Dose Ranging Efficacy and Safety with Mepolizumab in Severe Asthma (DREAM). Available from: clinicaltrials.gov/ct2/show/NCT01000506. Updated 2010 Jul 15.

91. Black PN, Udy AA, Brodie SM. Sensitivity to fungal allergens is a risk factor for life-threatening asthma. Allergy. 2000;55(5):501-504.

92. Fairs A, Agbetile J, Hargadon B, et al. IgE sensitisation to aspergillus fumigatus is associated with reduced lung function in asthma. Am J Respir Crit Care Med. 2010;201001-0087OC.

93. Denning DW, O'Driscoll BR, Hogaboam CM, Bowyer P, Niven RM. The link between fungi and severe asthma: a summary of the evidence. Eur Respir J. 2006;27(3):615-626.

94. Wark PA, Gibson PG, Wilson AJ. Azoles for allergic bronchopulmonary aspergillosis associated with asthma. Cochrane Database Syst Rev. 2003;(3):CD001108.

95. Denning DW, O'Driscoll BR, Powell G, et al. Randomized controlled trial of oral antifungal treatment for severe asthma with fungal sensitization: The Fungal Asthma Sensitization Trial (FAST) study. Am J Respir Crit Care Med. 2009;179(1):11-18.

96. Hope WW, Billaud EM, Lestner J, Denning DW. Therapeutic drug monitoring for triazoles. Curr Opin Infect Dis. 2008;21(6):580-586.

97. Castro M, Rubin AS, Laviolette M, et al. Effectiveness and safety of bronchial thermoplasty in the treatment of severe asthma: a multicenter, randomized, double-blind, sham-controlled clinical trial. Am J Respir Crit Care Med. 2010;181(2):116-124.

98. Pavord ID, Cox G, Thomson NC, et al. Safety and efficacy of bronchial thermoplasty in symptomatic, severe asthma. Am J Respir Crit Care Med. 2007;176(12):1185-1191.

Journal of Asthma and Allergy

\section{Publish your work in this journal}

The Journal of Asthma and Allergy is an international, peer-reviewed open-access journal publishing original research, reports, editorials and commentaries on the following topics: Asthma; Pulmonary physiology; Asthma related clinical health; Clinical immunology and the immunological basis of disease; Pharmacological interventions and

new therapies. Issues of patient safety and quality of care will also be considered. The manuscript management system is completely online and includes a very quick and fair peer-review system, which is all easy to use. Visit http://www.dovepress.com/testimonials.php to read real quotes from published authors. 